\title{
A progressividade do imposto de renda da pessoa física no Brasil
}

\author{
Fábio Avila de Castro \\ Doutorando - Universidade de Brasília \\ Endereço: Campus Universitário Darcy Ribeiro, Asa Norte - Brasília/DF \\ CEP: 70910-900 - E-mail: fabioavcastro@yahoo.com.br \\ Maurício Soares Bugarin \\ Professor Titular - Universidade de Brasília \\ Endereço: Campus Universitário Darcy Ribeiro, Asa Norte - Brasília/DF \\ CEP: 70910-900 - E-mail: bugarin.mauricio@gmail.com
}

Recebido: 18/11/2014. Aceite: 06/03/2017.

\section{Resumo}

O presente trabalho tem como objetivo avaliar a progressividade do Imposto de Renda da Pessoa Física no Brasil, no período de 2006 a 2012, utilizando números índices que permitem sua comparação com outros países. Dentre as medidas de progressividade efetiva ou global, foram calculados os índices de desvio da proporcionalidade de Kakwani e Suits, além dos índices de capacidade redistributiva de Reynolds-Smolensky, Musgrave-Thin e Pfähler. Mostra-se que o tributo brasileiro apresenta índices de progressividade bastante altos em comparação a países da América Latina e países desenvolvidos. Entretanto, sua capacidade redistributiva é limitada pela baixa representatividade da arrecadação do imposto em relação à renda bruta total do país, problema semelhante a muitos países com renda per capita similar à do Brasil. Efetuou-se também a decomposição da progressividade da estrutura do imposto, verificando-se que, no caso brasileiro, o efeito alíquota é responsável por toda a progressividade, enquanto o efeito base é proporcional.

\section{Palavras-Chave}

Imposto de renda da pessoa física. Incidência do imposto. Progressividade do imposto.

\begin{abstract}
The goal of this work is evaluate the progressivity of Brazilian personal income tax from 2006 to 2012, using index numbers that allows comparisons with other countries. Among measures of effective or global progression, this paper calculates the Kakwani's and Suit's indexes of departure from proportionality and the Reynolds-Smolensky's, Musgrave-Thin's and Pfähler's indexes of redistributive capacity. The results show that the Brazilian personal income tax exhibits high progressivity compared with Latin American and developed countries. On the other hand, the redistributive capacity of the personal income tax is limited due to its low revenue compared with national gross income, a problem also faced by countries with per capita income similar to Brazil's. The paper also calculates the progressivity decomposition of personal income tax structure, and finds that the tax-rate effect is responsible for the entire progressivity while the base effect is proportional.
\end{abstract}




\section{Keywords}

Personal income tax. Tax incidence. Tax progressivity.

\section{JEL Classification}

H22. H23. H24.

\section{Introdução}

O Estado moderno exerce um papel importante na moldagem da distribuição de renda e do bem-estar entre seus cidadãos, moderando as desigualdades geradas pela economia de mercado. Ele busca esses objetivos por intermédio de várias políticas públicas, como o estabelecimento do arcabouço legal do ambiente de negócios, a regulação da concorrência econômica, a provisão de bens e serviços públicos, a promoção de transferências monetárias às famílias de baixa renda e a arrecadação dos tributos necessários a seu financiamento.

Segundo Musgrave (1980), uma das principais funções do Estado sob a ótica das finanças públicas é a função redistributiva. Essa função está basicamente associada a ajustamentos no perfil da distribuição de renda, uma vez que as alocações de mercado podem levar a uma situação de desigualdade não apoiada pelos anseios gerais da população de um país. Neste caso, o equilíbrio de mercado pode passar a gerar conflitos e a interferir no funcionamento da própria sociedade.

Um importante instrumento à disposição do Estado para exercer sua função distributiva é, naturalmente, o sistema tributário. Por meio dele, o governo pode ajustar a renda dos cidadãos, taxando mais algumas rendas e menos outras, de forma a atingir uma distribuição final mais equitativa. Um sistema tributário progressivo é aquele no qual os impostos aumentam mais que proporcionalmente com o aumento da renda dos contribuintes. O sistema é regressivo quando o pagamento dos impostos aumenta menos que proporcionalmente com a renda dos contribuintes e proporcional (ou neutro) quando os impostos aumentam proporcionalmente com a renda (STIGLITZ, 2000:159). 
Um sistema de impostos progressivo tende, naturalmente, a reduzir a desigualdade de renda entre os cidadãos. No contexto do sistema tributário de qualquer país, o tributo que melhor possibilita a aplicação do princípio da progressividade é o Imposto de Renda da Pessoa Física (IRPF). Para avaliar-se a progressividade de um tributo foram criados índices de medida da progressividade estrutural ou local, como a alíquota efetiva, por exemplo, os quais utilizam a própria configuração do tributo e índices de medida da progressividade efetiva ou global, os quais utilizam medidas de desigualdade de renda antes e após a incidência do tributo. Os índices de Kakwani e Suits são exemplos desse tipo de índice, os quais serão apresentados em detalhe na seção 3 deste artigo.

O objetivo deste artigo é avaliar a progressividade do IRPF brasileiro, utilizando índices de avaliação da progressividade de um tributo com utilização consagrada na literatura econômica. Os índices de progressividade foram calculados para o período de 2006 a 2012, e foram efetuadas comparações com países integrantes da Organização para a Cooperação e Desenvolvimento Econômico (OCDE) e países da América Latina, ficando evidente a elevada progressividade do imposto no Brasil. Ressalta-se que este trabalho utilizou dados provenientes das Declarações de Imposto de Renda da Pessoa Física (DIRPF), os quais se mostram mais adequados que as pesquisas amostrais para a realização dos cálculos. A principal contribuição da presente pesquisa é permitir aos formuladores de política tributária avaliar a progressividade do IRPF ajudando a conhecer quem, de fato, suporta a carga tributária. Além disso, o artigo fornece subsídio para o recente debate acadêmico sobre as diversas alternativas para se melhorar a tributação direta no Brasil, de forma a alterar o perfil de incidência da carga tributária, atualmente centrado nos tributos incidentes sobre o consumo de bens e serviços. Por fim, ressalta-se que este artigo vem compor uma literatura recente de pesquisas empíricas sobre a progressividade dos tributos no Brasil.

Os principais resultados encontrados são que o IRPF brasileiro apresenta elevada progressividade em termos de desvio da proporcionalidade, e moderada capacidade redistributiva, em função da baixa representatividade da arrecadação frente à renda bruta total do país. Foi encontrado ainda que a progressividade do tributo brasileiro advém essencialmente da estrutura de alíquotas, sendo que a estrutura das deduções do rendimento bruto é proporcional, e, portanto, neutra em termos de progressividade. 
Além desta introdução, o artigo inclui, na seção 2, uma breve descrição da literatura existente. A seção 3 detalha o conceito de progressividade e apresenta as fórmulas dos principais índices de progressividade utilizados neste trabalho. A seção 4 descreve a construção da base de dados usada no presente artigo. A seção 5 apresenta os principais resultados encontrados a respeito da progressividade do IRPF no país. Finalmente, a seção 6 sumariza as principais contribuições deste trabalho.

\section{Incidência tributária e progressividade: breve descrição da lite- ratura}

Há extensa literatura internacional e nacional sobre o tema da incidência tributária e da progressividade dos tributos. Em benefício da concisão, apresentaremos aqui apenas uma breve descrição das principais referências pertinentes.

Quanto aos principais índices de medição de progressividade, o trabalho seminal é Musgrave e Thin (1948). Além disso, os trabalhos de Kakwani (1977) -que desenvolve um índice baseado em curvas de concentração - e Suits (1977) - que adota enfoque semelhante, mas com base em curvas de concentração relativas ordenadas pela renda são fundamentais para a compreensão das métricas de progressividade tributária. Sob a ótica da redistributividade, os trabalhos de Reynolds e Smolensky (1977) e Pfhäler (1990) são fundamentais para entender-se a ligação entre os diversos índices e o que eles procuram medir. Todos os trabalhos citados nos dois parágrafos anteriores serviram de base para o desenvolvimento teórico apresentado na seção 3.

Sobre os estudos empíricos de progressividade baseados em microdados, há extensa produção internacional e nacional, sendo que serão citados somente os estudos mais relevantes para o desenvolvimento deste projeto.

Nos países desenvolvidos, há vários trabalhos avaliando a progressividade dos tributos, como os de Slemrod (1996), Piketty e Saez (2007), Kim e Lambert (2009) e Mathews (2014), para os Estados Unidos; e Kesselman e Cheung (2004) para o Canadá. No âmbito da OCDE, há estudos comparativos importantes como os de Nooregard (1990); 
Verbist (2004); Verbist e Figari (2013); e Paturot, Mellbye e Bris (2013).

Em relação à América Latina (AL), contudo, há poucos trabalhos de avaliação da progressividade dos sistemas tributários. Um estudo abrangente é o de Goñi, López e Servén (2008), que apresenta uma interessante visão geral da questão fiscal e de equidade no contexto da AL. Para a América do Sul, há os estudos de Jorrat (2010) para o Chile e Roca (2010) para o Uruguai. Os trabalhos citados nos dois parágrafos anteriores apresentam os cálculos dos índices de progressividade que serviram para a comparação apresentada na seção 5 . No Brasil, no que diz respeito à progressividade da tributação direta e indireta há os estudos de Rodrigues (1998), que apresenta evidência empírica de carga tributária regressiva para os impostos sobre consumo e para a contribuição previdenciária sobre a folha salarial e de carga tributária progressiva para os tributos sobre a renda do trabalho; Paes e Bugarin (2006) apontam evidência empírica para a progressividade da tributação direta e para a proporcionalidade do sistema tributário; Immervoll et al. (2006) estimam a carga tributária da tributação direta como sendo progressiva e mostram que o sistema tributário possui um caráter redistributivo baixo; Silveira (2010) aponta para o reduzido impacto distributivo dos benefícios previdenciários e assistenciais e do seguro-desemprego, e mostra que a progressividade da tributação direta acaba sendo neutralizada pela regressividade da tributação sobre o consumo. Por sua vez, o estudo de Payeras (2010) avaliou a progressividade da distribuição da carga tributária sobre a população, considerando as alíquotas de ICMS de todos os Estados da federação, e concluiu que a carga tributária é regressiva quando tomada a renda como base, devido à baixa participação da tributação direta na carga e à seleção insatisfatória dos produtos na tributação do consumo das famílias; o de Azevedo (2003) avaliou o papel dos tributos no financiamento das transferências governamentais, concluindo que as transferências de renda líquida contribuem para a diminuição das desigualdades regionais e os de Siqueira et al. (2000, 2010), que investigaram a progressividade dos tributos sobre o consumo, concluindo que mais de um terço dos tributos indiretos no país incide sobre insumos e que as alíquotas efetivas sobre o consumo das famílias variam enormemente entre os produtos. Esses trabalhos serviram, em sua maior parte, de comparação para os achados efetuados em nossa pesquisa, apesar de não abordarem especificamente o IRPF. 
Para o caso específico do IRPF, os trabalhos são esparsos, sendo os principais precursores a este estudo os trabalhos de Rossi (1983), que calculam o índice de Kakwani para os rendimentos do trabalho considerando somente o universo de declarantes que entregaram a DIRPF em 1980, obtendo índice de 0,418, que demonstra elevado desvio da proporcionalidade, assim como uma redistributividade limitada por conta do pequeno universo de declarantes e da baixa representatividade arrecadatória frente à renda bruta total do país; Rocha (2002) aponta que o potencial distributivo restrito do imposto de renda no Brasil está essencialmente vinculado à forte desigualdade na distribuição da renda bruta, uma vez que a elevada frequência de rendimentos baixos, portanto isentos do imposto de renda, inviabiliza a tributação do IRPF como mecanismo distributivo privilegiado, como ocorre em países desenvolvidos, e Soares et al. (2010) que, a partir dos microdados da PNAD, fizeram uma simulação de incidência do IRPF, chegando a uma curva de concentração para o IRPF bastante semelhante à encontrada neste trabalho, que demonstrava o elevado desvio da proporcionalidade, assim como uma redistributividade limitada e estável do IRPF para o período de 2002 a 2007.

\section{Progressividade: conceito e medidas}

\subsection{Progressividade de um tributo}

Diz-se que um tributo é progressivo se a alíquota média (também chamada de alíquota efetiva) atribuída a uma "unidade tributável", aumenta na medida em que cresce sua renda. Isso significa que uma unidade com maior renda não só paga mais tributo, mas também perde uma parcela maior de sua renda pagando o imposto.

$\mathrm{Na}$ literatura econômica recente há uma extensa variedade de medidas de progressividade para os tributos ou sistemas tributários, sendo que não existe uma medida única ou universalmente usada. Por exemplo, em seu trabalho seminal, Musgrave e Thin (1948) apresentaram vários indicadores de progressividade e os distinguiram entre indicadores de progressividade estrutural e de progressividade efetiva, referidos também como indicadores de progressividade local ou global, respectivamente. A principal diferença entre essas duas classificações é que os 
indicadores locais medem a progressividade com base na configuração do tributo, ao passo que os globais o fazem com base em alguma medida de desigualdade de renda antes e após a incidência do tributo. O presente trabalho terá como foco principal as medidas de progressividade efetiva ou global, uma vez que uma desvantagem das medidas locais é que elas não permitem o ordenamento da progressividade dos tributos sem ambiguidade (LAMBERT, 2001:196), sendo as possíveis comparações limitadas a um certo nível de renda ou para faixas de renda. Pode-se mostrar, matematicamente, seguindo Lambert (2001:39), que a distribuição de renda líquida (após imposto) será menos desigual do que a distribuição de renda bruta (antes do imposto), se e somente se, o imposto incidir de forma desigual sobre a renda bruta, concentrando maior gravame sobre as rendas mais elevadas.

Como uma das consequências da definição de progressividade (alíquota média crescente com a renda) é a incidência desigual do imposto (grava mais fortemente as rendas mais altas), então um tributo progressivo exerce um efeito equalizador na distribuição de renda, sendo que esse efeito equalizador é também conhecido como efeito redistributivo do imposto.

\subsection{O Índice de Kakwani e o Índice de Suits}

Pode-se inferir da exposição feita no item anterior, que a imposição tributária desvia-se da proporcionalidade em relação à renda bruta (antes da incidência do imposto) no caso de um imposto progressivo, sendo essa a lógica que sustenta a proposição dos índices a serem apresentados.

Kakwani (1977) observou que a desproporcionalidade da incidência do imposto era evidenciada pela separação das curvas de Lorenz da renda bruta $\left(L_{X}\right)$ e a Curva de Concentração ${ }^{1}$ do imposto $\left(L_{T}\right)$. Desse modo, propôs um índice de progressividade que pode ser calculado

\footnotetext{
1 A curva de Concentração é construída a partir da distribuição de duas variáveis na população, em que a variável de ordenação não coincide com a variável de distribuição. Assim, por exemplo, pode-se traçar uma curva de concentração da proporção acumulada dos rendimentos do trabalho contra a proporção acumulada da população de trabalhadores ordenados por sua renda familiar per capita. Portanto, a Curva de Lorenz é um caso particular da curva de Concentração para o caso em que a variável de ordenação e distribuição coincidem.
} 
como a diferença entre o índice de concentração ${ }^{2}$ dos impostos (ordenados pela renda bruta) e o índice de Gini associado à Curva de Lorenz. Matematicamente tem-se que:

$$
\Pi^{K}=C_{T}-G_{X}
$$

Onde: $G_{X}$ é o coeficiente de Gini da renda bruta e $C_{T}$ é o coeficiente de concentração do tributo.

Assim, se $\Pi^{K}>0$ o imposto é progressivo, se $\Pi^{K}=0$ o imposto é proporcional e se $\Pi^{K}<0$ o imposto é regressivo. O índice de Kakwani pode ainda ser calculado como o dobro da área compreendida entre a curva de concentração do imposto e a curva de Lorenz da renda bruta.

Uma maneira diferente de olhar a mesma situação foi proposta por Suits (1977). Assim, Suits desenvolveu uma análise baseada em curvas de concentração relativas, ao invés de curvas de concentração, para examinar a desproporcionalidade. A ideia é considerar a concentração do imposto diretamente como função da concentração da renda bruta (antes da incidência do imposto). Portanto, a curva de concentração relativa para o tributo $R_{T}(q)$ apresenta a distribuição acumulada do imposto em função das frações acumuladas da renda bruta. Para um imposto de alíquota única $R_{T}(q)=q$; que representa uma linha de $45^{\circ}$ que funciona como referência para a tributação proporcional. Além disso, $R_{T}(q)$ será crescente e convexa se o tributo for progressivo. Desse modo, Suits define o desvio da proporcionalidade como o dobro da área entre a curva de concentração relativa $R_{T}(q)$ para os tributos e a reta de $45^{\circ}$ da tributação proporcional.

A notação usada para o índice de Suits é $\Pi^{S}$ e o imposto será progressivo se $\Pi^{S}>0$; regressivo se $\Pi^{S}<0$ e proporcional se $\Pi^{S}=0$. Uma propriedade atrativa do índice de Suits, não compartilhada pelo índice de Kakwani, é que seu valor varia entre -1 (extrema regressividade) e 1 (extrema progressividade). Os limites do índice de Kakwani, por outro lado, dependem da desigualdade da distribuição da renda bruta. Eles são: $\left(-1-G_{X}\right)$ para máxima regressividade e $\left(1-G_{X}\right)$ para máxima progressividade. Feitas essas considerações, apresentar-se-á alguns outros índices de progressividade mais focados nos efeitos redistributivos da tributação.

2 O índice de concentração é definido da mesma forma que o índice de Gini, como sendo o dobro da área entre a curva de concentração e a reta da perfeita igualdade. 


\subsection{Os Índices de Reynolds-Smolensky, Musgrave-Thin e Pfähler}

Assim como os índices de Kakwani e Suits quantificam a desproporcionalidade da tributação em termos da separação entre as curvas $L_{X}$ e $L_{T}$, os correspondentes índices de efeito redistributivo podem ser compreendidos em termos da separação entre as curvas de Lorenz da renda bruta $\left(L_{X}\right)$ e a curva de Lorenz da renda líquida $\left(L_{X-T}\right)$. Define-se:

$$
\Pi^{R S}=G_{X}-C_{X-T}
$$

Onde: $G_{X}$ é o coeficiente de Gini da renda bruta e $C_{X-T}$ é o coeficiente de concentração da renda líquida, que se iguala ao coeficiente de Gini sem efeito de reordenamento. ${ }^{3} \mathrm{O}$ índice $\Pi^{R S}$ mede, portanto, a redução no coeficiente de Gini alcançada pela tributação. Foi nomeado após os economistas Reynolds e Smolensky (1977) o terem aplicado ao sistema tributário americano. Analogamente aos outros índices, também pode ser obtido calculando-se o dobro da área entre as curvas $L_{X}$ e $L_{X-T}$.

Outro índice de redistributividade foi proposto por Pfähler (1985) e difere do índice de Reynolds e Smolensky, da mesma forma que o índice de Suits difere do índice de Kakwani. O índice $\Pi^{P A}$ pode ser calculado como o dobro da área entre a curva de concentração relativa da renda líquida $R_{T-X}(q)$ e a reta de $45^{\circ}$ da tributação proporcional. Um índice mais antigo e menos usado atualmente é o de Musgrave e Thin (1948), o qual os autores denominaram de progressividade efetiva, e que se baseia, assim como $\Pi^{R S}$, nos índices de Gini da renda bruta e da renda líquida. Assim:

$$
\Pi^{M T}=\frac{1-G_{X-T}}{1-G_{X}}
$$

Onde: $G_{X}$ é o coeficiente de Gini da renda bruta e $G_{X-T}$ : Índice de Gini da renda líquida (renda bruta menos IRPF). Tem-se que o imposto será progressivo se $\Pi^{M T}>1$; regressivo, se $\Pi^{M T}<1$; e proporcional, se $\Pi^{M T}=1$.

3 O efeito de reordenamento ocorre quando parâmetros diversos da renda influenciam o cálculo do imposto. Essa é uma característica dos sistemas de impostos modernos e pode levar a alterações no ordenamento da população após a incidência tributária. Tal efeito não será considerado neste trabalho. 
Uma importante observação é que desproporcionalidade e redistributividade são dois lados da mesma moeda. Com um tributo progressivo, parte da carga tributária é deslocada para as rendas mais altas e, consequentemente, os percentuais de renda líquida apropriados por cada faixa de renda se modificam. Claramente os dois efeitos estão conectados. Pode-se mostrar que o efeito redistributivo é determinado pelo desvio da proporcionalidade (progressividade) e pelo nível de tributação expresso pela razão $\frac{g}{1-g}$, em que o parâmetro $g$ representa a razão entre a arrecadação do tributo e a renda bruta total do país. Assim:

$$
\begin{aligned}
& \Pi^{R S}=\frac{g}{1-g} \Pi^{K} ; \mathrm{e} \\
& \Pi^{P A}=\frac{g}{1-g} \Pi^{S}
\end{aligned}
$$

Desse modo, os índices apresentados serão utilizados de acordo com a perspectiva que se deseja avaliar do tributo. A alíquota média faz uma avaliação da configuração do imposto (base de cálculo, alíquotas, deduções, etc.), ao passo que os índices de Kakwani e Suits buscam avaliar o quanto a incidência do imposto se desvia da distribuição da renda antes da incidência tributária. Já os índices de Musgrave e Thin; Reynolds e Smolensky e Pfhäler procuram avaliar o efeito redistributivo do imposto, comparando a distribuição da renda antes e após sua incidência. Todos os índices citados foram calculados neste trabalho, de forma a se apresentar a avaliação mais ampla possível do IRPF no país.

\section{A construção da base de dados}

No caso do presente trabalho foram utilizados microdados de todas as declarações de IRPF para o período de 2006 a 2012. As informações foram extraídas da base de dados da Secretaria da Receita Federal do Brasil (RFB) por meio de um sistema de Data Warehouse (DW), que permite a manipulação de um grande volume de dados. Ressalta-se que 
todos os cálculos são feitos para valores correntes, não havendo nenhuma atualização para valores presentes.

Apesar da vantagem na utilização da base completa do IRPF, houve a necessidade de uma grande depuração, uma vez que muitas declarações contêm informações incorretas que provocavam grandes distorções nos dados obtidos. Não foi possível realizar a depuração completa dos diversos dados extraídos, mas a inspeção dos valores de rendimento tributável, rendimento sujeito à tributação exclusiva, rendimento isento, valor agregado de bens e direitos e valor agregado de algumas deduções do imposto de renda bruto, resultaram na exclusão da base de, aproximadamente, 2.800 contribuintes no contexto de todos os anos examinados.

Como nem todas as pessoas que possuem rendimentos são obrigadas à entrega da DIRPF, houve a necessidade de que se complementasse a base de dados com os rendimentos das pessoas isentas da entrega da declaração. A base de dados foi complementada, então, utilizando-se a Pesquisa Nacional por Amostra de Domicílios (PNAD), realizada anualmente, e pelo Censo para o ano específico de 2010. Foram utilizadas as Tabelas 4.1 do Volume Brasil ${ }^{4}$ da PNAD para todos os anos, exceto 2010, e a Tabela 1.8.1 do Censo 2010. Essas tabelas contêm informações dos rendimentos mensais dos indivíduos para todo o Brasil, separadas em oito faixas indexadas ao salário mínimo, as quais originaram faixas de rendimento bruto anual que foram utilizadas para a extração de dados das declarações do IRPF de cada ano. No caso da Tabela 1.8.1 do Censo 2010, existem 11 faixas que puderam ser readequadas para as respectivas faixas da PNAD. Optou-se por utilizar as citadas tabelas da PNAD com oito faixas de renda, pois eram as únicas que possuíam os limites de cada faixa, ainda que a utilização de um maior número de faixas conduzisse a resultados com maior precisão.

Assim, como na PNAD as pessoas são solicitadas a informar a sua renda bruta, foi criada uma variável denominada renda bruta no sistema $D W$, de forma que os contribuintes pudessem ser ordenados nas faixas de acordo com ela. A variável renda bruta se constituía na soma dos rendimentos tributáveis, dos rendimentos sujeitos à tributação exclusiva e dos rendimentos isentos e não tributáveis. Destaca-se que essa variável foi criada exclusivamente para a ordenação das declarações, mantendose a informação da renda bruta informada na PNAD para fins de cálculo

4 Cf. INSTITUTO BRASILEIRO DE GEOGRAFIA E ESTATístiCA. Pesquisa Nacional por Amostra de Domicílios: Volume Brasil. 
da distribuição dos rendimentos. Importante também lembrar que o exame do questionário da PNAD permite concluir que, teoricamente, a renda bruta declarada na PNAD equivale à renda bruta declarada na DIRPF. Naturalmente, sofremos com a expectativa de que as rendas das aplicações financeiras e as rendas isentas não sejam tão bem captadas na PNAD.

Outra inovação trazida foi a estimativa do imposto sobre os rendimentos do capital feita com base nas declarações de IRPF apresentadas e nos dados de arrecadação federal, uma vez que se considera que os rendimentos do capital são uma informação mal captada pela PNAD conforme assevera Rocha (2002).

Feitas essas breves considerações metodológicas, passa-se ao cálculo dos índices de progressividade para o IRPF.

\section{Resultados}

\subsection{Progressividade local: alíquota efetiva}

A medida de progressividade local mais comumente utilizada é a alíquota média ou efetiva, obtida dividindo-se o imposto devido da faixa de renda pela renda bruta da referida faixa. As alíquotas efetivas do IRPF trabalho e IRPF capital foram calculadas a partir das declarações de IRPF e as alíquotas efetivas foram obtidas dividindo-se o IRPF trabalho e o IRPF capital pelos rendimentos tributáveis (incluídos os rendimentos do $13^{\circ}$ salário) e pelos rendimentos com tributação exclusiva na fonte (excluídos os rendimentos oriundos do $13^{\circ}$ salário), respectivamente. A alíquota do IRPF total equivale à divisão da soma de IRPF trabalho e o IRPF capital pela soma dos rendimentos tributáveis com os rendimentos com tributação exclusiva na fonte para cada um dos anos apresentados.

A Tabela 1 mostra a evolução das alíquotas efetivas do IRPF trabalho, do IRPF Capital e do IRPF Total no período de 2006 a 2012, lembrando que no IRPF trabalho está incluso a parcela referente ao $13^{\circ}$ salário, o qual é submetido à tributação exclusiva na fonte. 
Tabela 1 - Alíquotas efetivas para IRPF Trabalho, IRPF Capital e IRPF Total para o período de 2006 a 2012

\begin{tabular}{cccc}
\hline Ano & $\begin{array}{c}\text { Alíquota Efetiva } \\
\text { IRPF Trabalho (\%) }\end{array}$ & $\begin{array}{c}\text { Alíquota Efetiva } \\
\text { IRPF Capital (\%) }\end{array}$ & $\begin{array}{c}\text { Alíquota Efetiva } \\
\text { IRPF Total (\%) }\end{array}$ \\
\hline $\mathbf{2 0 0 6}$ & 8,0 & 18,1 & 8,5 \\
$\mathbf{2 0 0 7}$ & 8,1 & 17,9 & 8,9 \\
$\mathbf{2 0 0 8}$ & 8,5 & 15,0 & 8,9 \\
$\mathbf{2 0 0 9}$ & 8,1 & 14,5 & 8,4 \\
$\mathbf{2 0 1 0}$ & 8,8 & 13,4 & 8,8 \\
$\mathbf{2 0 1 1}$ & 9,1 & 12,9 & 9,1 \\
$\mathbf{2 0 1 2}$ & 8,9 & 14,8 & 9,2 \\
\hline
\end{tabular}

Fonte: DW IRPF (RFB) / Elaboração Própria.

O exame da Tabela 1 mostra um aumento nas alíquotas efetivas da tributação do trabalho, passando de um patamar de $8 \%$ para um patamar de $9 \%$, denotando um crescimento de $12,5 \%$ ao longo de sete anos. Um fato importante a ser lembrado é que boa parte do aumento da alíquota efetiva do IRPF Trabalho está relacionado à correção abaixo da inflação na tabela do tributo no período. As alíquotas efetivas do IRPF Capital decresceram, aproximadamente, $18 \%$ no período, passando de $18,1 \%$ em 2006 para 14,8\% em 2012. Os anos de 2006 e 2007 apresentaram alíquotas efetivas mais altas devido às arrecadações extraordinárias decorrentes da venda de participações societárias, principalmente em Bolsa de Valores. Uma provável explicação para o aumento da alíquota efetiva do IRPF Capital em 2012 foi a manutenção da taxa básica de juros ao redor de $11 \%$ ao ano ao longo do ano de 2011, o que causou, certamente, reflexo na arrecadação do ano de 2012 em relação aos investimentos de renda fixa. O resultado para 2012 mostra que há espaço para uma tributação adicional dos rendimentos do capital, lembrandose, por exemplo, as isenções existentes para o ganho de capital na venda de imóveis e as isenções concedidas às operações com renda variável. Com relação às alíquotas efetivas do IRPF total, nota-se um leve aumento, mas em menor ritmo. Pode-se verificar que as alíquotas efetivas são baixas quando se lembra, por exemplo, que a alíquota marginal mínima do IRPF trabalho é 7,5\% e a alíquota marginal do capital é, grosso modo, de $15 \%$. Isso demonstra a progressividade do imposto, uma vez que a maioria dos contribuintes é tributada a uma alíquota efetiva próxima ou inferior às alíquotas marginais mínimas. $\mathrm{O}$ foco das próximas seções são as medidas de progressividade global do IRPF. 


\subsection{Desvio da proporcionalidade: Índice de Kakwani e Índice de Suits.}

Tanto para o cálculo de $\Pi^{K}$ como para $\Pi^{S}$ precisa-se da distribuição da população, da renda bruta e do IRPF entre as faixas de renda trazidas da PNAD. No cálculo do índice de Gini foi considerada a renda bruta declarada na PNAD para todas as faixas.

O imposto de renda oriundo dos rendimentos do trabalho foi obtido pela soma do imposto devido na declaração de ajuste anual mais uma estimativa do imposto devido pelo $13^{\circ}$ salário. É importante lembrar que o $13^{\circ}$ salário sofre tributação exclusiva na fonte, submetida à tabela progressiva de cada ano. A apuração do imposto não transita na DIRPF, mas o contribuinte informa na declaração o valor do $13^{\circ}$ salário, o que permitiu a estimativa de valores para cada faixa, conforme as alíquotas marginais estabelecidas na legislação para cada ano e considerando-se as declarações com $13^{\circ}$ maior que zero para cada faixa.

Para o imposto de renda originado dos rendimentos do capital, foram somadas quatro parcelas diferentes: o valor do imposto pago na alienação de bens e direitos (declarado na DIRPF); o valor do imposto pago decorrente de ganhos no mercado de renda variável (declarado na DIRPF); o valor do imposto pago decorrente do ganho de capital na alienação de moeda estrangeira (declarado na DIRPF) e o valor do imposto pago sobre aplicações financeiras de renda fixa. As duas primeiras parcelas são informadas na DIRPF, mas não foi feita nenhuma depuração desses valores e, além disso, o programa gerador da declaração não faz nenhuma crítica aos valores informados. Felizmente há dois códigos de arrecadação: 4600 (IRPF - ganho de capital na alienação de bens e direitos) e 6015 (IRPF - Ganhos no mercado de renda variável) que serviram de ajuste aos valores apresentados na declaração. Para os anos de 2006 a 2012, os valores informados na declaração foram sempre inferiores à arrecadação dos códigos, de forma que a arrecadação dos códigos foi distribuída proporcionalmente entre as faixas de acordo com a informação prestada na declaração. $O$ valor do imposto pago na alienação de moeda estrangeira não traz valores expressivos e foi retirado da DIRPF sem a necessidade de qualquer acerto. Finalmente, há a parcela relativa às aplicações de renda fixa. Os declarantes informam na DIRPF os rendimentos líquidos recebidos nas aplicações financeiras, mas não o imposto pago decorrente das aplicações. A estimativa do valor foi feita utilizando-se a seguinte equação: 


\section{Rendimento líquido $=$ Rendimento Bruto - \\ (Rendimento Bruto x alíquota média)}

As alíquotas marginais para rendimentos do capital oriundos de aplicações de renda fixa variam entre $15 \%$ e $22,5 \%$, sendo que a alíquota média foi calculada para cada ano fazendo-se proporções com códigos de arrecadação que agregam pessoa física e pessoa jurídica. A alíquota média situou-se sempre entre $15 \%$ e $17 \%$. A Tabela 2 foi utilizada para o cálculo dos índices de progressividade para 2012. O IRPF Capital não foi calculado para as pessoas abaixo do limite de isenção, pois isso não era possível nesse exercício. No entanto, estimamos que pessoas com ganhos anuais abaixo de meio-salário mínimo, muito provavelmente, terão seus investimentos, no máximo, em caderneta de poupança, isenta de IR. Não resta a menor dúvida que o pagamento eventual de ganho de capital é plausível, mas entendemos que isso não nos levaria a valores significativos, a princípio.

Tabela 2 - Valores utilizados para o cálculo dos índices de Kakwani e Suits - 2012 Valores em $\mathbf{R} \$$ milhões

\begin{tabular}{ccrrrr}
\hline Faixa Rendimento Anual & № pessoas & $\begin{array}{c}\text { Renda Bruta } \\
\text { Anual }\end{array}$ & $\begin{array}{c}\text { Valor IRPF } \\
\text { Trabalho }\end{array}$ & $\begin{array}{c}\text { Valor IRPF } \\
\text { Capital }\end{array}$ & IRPF TOTAL \\
\hline Até 3.732 & 12.178 .323 & $25.136,06$ & 0,01 & 3,85 & 3,86 \\
Mais de 3.732 a 7.464 & 29.857 .867 & $207.094,17$ & 0,04 & 7,74 & 7,78 \\
Mais de 7.464 a 14.928 & 39.072 .265 & $433.233,27$ & 0,30 & 19,56 & 19,85 \\
Mais de 14.928 a 22.392 & 13.197 .578 & $240.882,19$ & 1,17 & 30,47 & 31,64 \\
Mais de 22.392 a 37.320 & 11.824 .922 & $340.132,06$ & 826,92 & 138,64 & 965,56 \\
Mais de 37.320 a 74.640 & 6.094 .781 & $321.365,61$ & $10.245,53$ & 500,73 & $10.746,25$ \\
Mais de 74.640 a 149.280 & 2.075 .849 & $214.925,10$ & $27.318,60$ & 988,51 & $28.307,11$ \\
Mais de 149.280 & 737.731 & $200.816,28$ & $70.251,11$ & $16.076,34$ & $86.327,45$ \\
\hline TOTAL & 115.039 .316 & $1.983 .584,74$ & $108.643,68$ & $17.765,83$ & $126.409,51$ \\
\hline
\end{tabular}

Fonte: PNAD (IBGE) e DW IRPF (RFB) / Elaboração Própria.

Com os valores da tabela acima foram calculados os seguintes valores utilizando-se a Equação (1): $\Pi^{K}=C_{T}-G_{X}$

Assim: $C_{T}=0,978, G_{X}=0,491$ e $\Pi^{K}=0,487$.

A Figura 1 apresenta a curva de Lorenz para o rendimento bruto e a curva de concentração para o imposto referentes ao ano de 2012. 


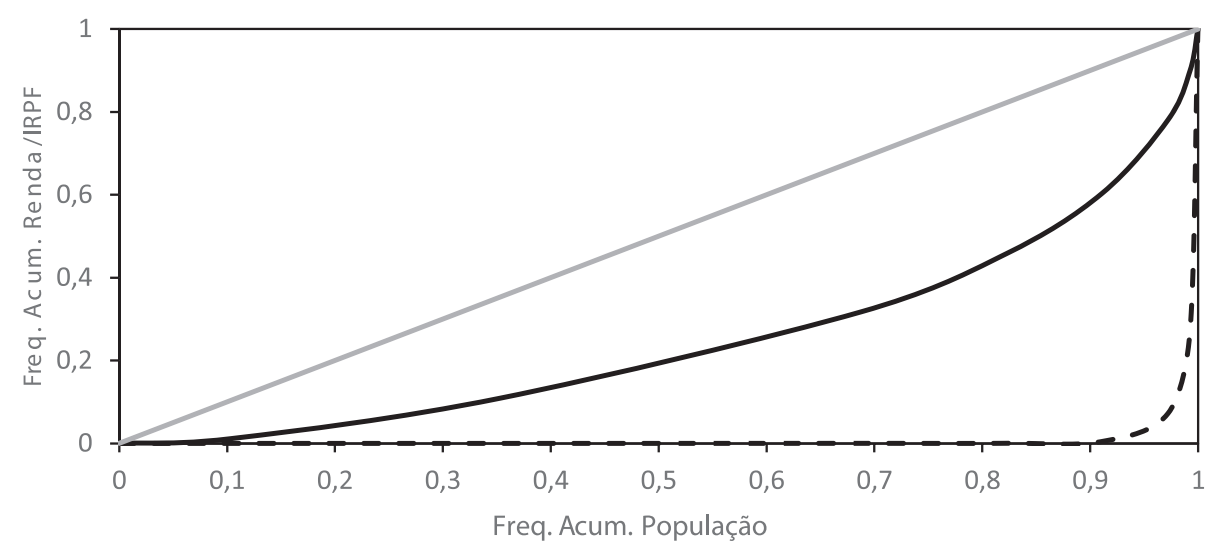

— Curva Lorenz Renda Bruta - - - Curva Conc. IRPF — Reta da Igualdade Perfeita

Figura 1 - Curva de Lorenz da Renda Bruta e Curva de Concentração do IRPF 2012

Fonte: PNAD (IBGE) e DW IRPF (RFB) / Elaboração Própria.

A Figura 1 mostra uma curva de Lorenz bastante desigual para os padrões mundiais, o que confirma fato assinalado em Barros et al. (2010). Mas a curva de concentração dos impostos é especialmente dramática, com a última faixa de renda respondendo por nada mais nada menos do que $68,3 \%$ do imposto de renda total, $64,7 \%$ do IRPF trabalho e $89,9 \%$ do IRPF capital. Rossi (1983) encontrou um índice de Kakwani de 0,418 para o ano de 1980, utilizando somente o universo de declarantes do IRPF e os rendimentos do trabalho. Resultado semelhante para a curva de concentração do IRPF foi encontrado, mais recentemente, por Soares et al. (2010) em estudo de mesma natureza, que utilizou os microdados da PNAD. Portanto, o IRPF brasileiro se apresenta como bastante focado no segmento populacional de renda mais elevada. Esse segmento tem facilidade para evitar as alíquotas mais elevadas relativas ao imposto sobre o rendimento do trabalho, uma vez que podem arcar com os custos da transformação em pessoa jurídica e, assim, conviver com alíquotas efetivas menores. Entretanto, é a faixa de renda que concentra praticamente todo o imposto sobre aplicações financeiras (IRPF capital) como mostra a Tabela 2, o que indicaria uma possível estratégia de política tributária (tributação de produtos financeiros isentos, por exemplo, aí incluída uma possível tributação sobre a distribuição de dividendos). Um outro aspecto que parece muito interessante, mas que foge ao escopo deste trabalho, é colocar uma lupa nesse segmento populacional, uma vez que as origens de renda e outras idiossincrasias 
merecem ser estudadas no sentido de se entender como formular políticas que possam gravar tributariamente essas pessoas, sem, no entanto, desincentivá-las a produzir e a beneficiar o país.

Antes de prosseguir, é viável explorar um resultado provado por Kakwani (1977) e que nos ajuda a decompor a progressividade do IRPF total em seus componentes relacionados ao trabalho e ao capital. Tratase da decomposição abaixo em que $i=1,2, \ldots, n$ corresponde às alíquotas do imposto $t_{i}$ e $t$ corresponde à alíquota total de todos os impostos.

$$
C_{I M P}=\sum_{i=1}^{n} \frac{t_{i}}{t} C_{I M P_{i}}
$$

A expressão acima indica que o coeficiente de concentração de um imposto é a soma dos coeficientes de concentração de seus $i$-ésimos componentes, ponderado pelas alíquotas médias de cada um deles. Daí decorre que:

$$
\Pi_{I M P}^{K}=\sum_{i=1}^{n} \frac{t_{i}}{t} C_{I M P_{i}}-\sum_{i=1}^{n} \frac{t_{i}}{t} G_{X}=\sum_{i=1}^{n} \frac{t_{i}}{t} \Pi_{I M P_{i}}^{K}
$$

De modo que a partir da Equação (7) obtém-se os seguintes resultados:

$$
\Pi_{T R A B}^{K}=0,418 ; \Pi_{C A P}^{K}=0,069 \text { e } \Pi_{I R P F}^{K}=0,487 .
$$

Dessa forma, observa-se que apesar de o IRPF capital ser mais concentrado que o IRPF trabalho, sua contribuição acaba sendo ponderada pela sua menor representatividade arrecadatória no contexto do imposto de renda total. Portanto, verifica-se que o maior peso à progressividade advirá dos rendimentos oriundos do trabalho. Prossegue-se agora para o cálculo da progressividade no contexto das curvas de concentração relativas.

Utilizando-se a mesma Tabela 2, calcula-se o índice de Suits. Assim, para 2012:

$$
\Pi^{S}=0,804
$$


Conclui-se, portanto, que pela filosofia de desvio da proporcionalidade, tanto pelo critério de Kakwani quanto pelo enfoque de Suits, o IRPF brasileiro é bastante progressivo. Os mesmos cálculos foram efetuados para o período de 2006 a 2011 utilizando-se as tabelas semelhantes à construída para o ano de 2012. Os resultados obtidos são mostrados na Tabela 3.

Tabela 3 - Índices de Kakwani e Suits calculados para o IRPF de 2006 a 2012

\begin{tabular}{ccccccc}
\hline & $C_{I R P F}$ & $G_{X}$ & $\Pi_{I R P F}^{K}$ & $\Pi_{T R A B}^{K}$ & $\Pi_{C A P}^{K}$ & $\Pi^{S}$ \\
\hline $\mathbf{2 0 0 6}$ & 0,976 & 0,534 & 0,442 & 0,395 & 0,047 & 0,788 \\
$\mathbf{2 0 0 7}$ & 0,972 & 0,521 & 0,451 & 0,384 & 0,067 & 0,782 \\
$\mathbf{2 0 0 8}$ & 0,977 & 0,518 & 0,458 & 0,394 & 0,064 & 0,799 \\
$\mathbf{2 0 0 9}$ & 0,979 & 0,510 & 0,469 & 0,413 & 0,056 & 0,814 \\
$\mathbf{2 0 1 0}$ & 0,980 & 0,513 & 0,467 & 0,408 & 0,059 & 0,802 \\
$\mathbf{2 0 1 1}$ & 0,978 & 0,494 & 0,484 & 0,412 & 0,072 & 0,817 \\
$\mathbf{2 0 1 2}$ & 0,978 & 0,491 & 0,487 & 0,418 & 0,069 & 0,804 \\
\hline
\end{tabular}

Legenda: $C_{I R P F}=$ Coeficiente de Concentração do IRPF; $G_{X}=$ Índice de Gini da renda Bruta; $\Pi_{I R P F}^{K}=$ Índice de Kakwani referente ao IRPF; $\Pi_{T R A B}^{K}=$ Índice de Kakwani referente ao IRPF trabalho; $\Pi_{C A P}^{K}=$ Índice de Kakwani referente ao IRPF capital e $\Pi^{S}=$ Índice de Suits.

Fonte: Elaboração Própria.

O que se nota da Tabela 3 é um aumento de 10,2\% no índice de Kakwani e uma correspondente diminuição de 8,1\% no índice de Gini da renda bruta entre 2006 e 2012. O coeficiente de concentração do IRPF manteve-se praticamente constante. O índice de Suits teve um aumento percentual de 2,03\%, mostrando uma variação coerente com o índice de Kakwani. O índice de Kakwani dos rendimentos do trabalho teve ligeiro aumento a partir de 2009 por conta da introdução de duas novas alíquotas na tabela progressiva, de $7,5 \%$ e $22,5 \%$. Já o índice de Kakwani dos rendimentos do capital oscilou, provavelmente acompanhando os principais parâmetros macroeconômicos que os influenciam, como taxa de juros e volume de aplicações no mercado financeiro, além de outros fatores, visto que a legislação não conheceu alterações significativas no período em questão. De forma geral, o IRPF conheceu um ligeiro aumento em termos de progressividade para o período examinado. Passa-se a examinar a outra faceta da progressividade, o potencial redistributivo do tributo, e os índices a ele ligados. 
5.3. Efeito redistributivo: Índices de Reynolds-Smolensky, Musgrave-Thin e Pfähler

Dentre os índices de efeito redistributivo, o que figura com mais frequência nos estudos comparativos é o índice de Reynolds-Smolensky. A Tabela 4 mostra os valores utilizados no cálculo dos três índices para o ano de 2012.

Tabela 4 - Valores utilizados para o cálculo dos índices redistributivos para 2012 Valores em $R \$$ milhões

\begin{tabular}{ccrrr}
\hline Faixa Rendimento Anual & No pessoas & $\begin{array}{c}\text { Renda Bruta } \\
\text { Anual }\end{array}$ & \multicolumn{1}{c}{ IRPF TOTAL } & \multicolumn{1}{c}{$\begin{array}{c}\text { Renda Líquida } \\
\text { Anual }\end{array}$} \\
\hline Até 3.732 & 12.178 .323 & $25.136,06$ & 3,86 & $25.132,20$ \\
Mais de 3.732 a 7.464 & 29.857 .867 & $207.094,17$ & 7,78 & $207.086,38$ \\
Mais de 7.464 a 14.928 & 39.072 .265 & $433.233,27$ & 19,85 & $433.213,42$ \\
Mais de 14.928 a 22.392 & 13.197 .578 & $240.882,19$ & 31,64 & $240.850,55$ \\
Mais de 22.392 a 37.320 & 11.824 .922 & $340.132,06$ & 965,56 & $339.166,50$ \\
Mais de 37.320 a 74.640 & 6.094 .781 & $321.365,61$ & $10.746,25$ & $310.619,36$ \\
Mais de 74.640 a 149.280 & 2.075 .849 & $214.925,10$ & $28.307,11$ & $186.617,99$ \\
Mais de 149.280 & 737.731 & $200.816,28$ & $86.327,45$ & $114.488,83$ \\
\hline TOTAL & 115.039 .316 & $1.983 .584,74$ & $126.409,51$ & $1.857 .175,23$ \\
\hline
\end{tabular}

Fonte: PNAD (IBGE) e DW IRPF (RFB) / Elaboração Própria.

A Figura 2 mostra as curvas de Lorenz para a Renda Bruta e a Renda Líquida, já adiantando que, no caso brasileiro, o efeito redistributivo do IRPF não é tão significativo. Isso mostra a importância de se calcular os diversos índices de progressividade, de forma a se ter uma noção mais precisa de quais fatores preponderam no contexto da estrutura do tributo, uma vez que um desvio tão pronunciado da proporcionalidade poderia, a princípio, sugerir um potencial redistributivo mais elevado. 


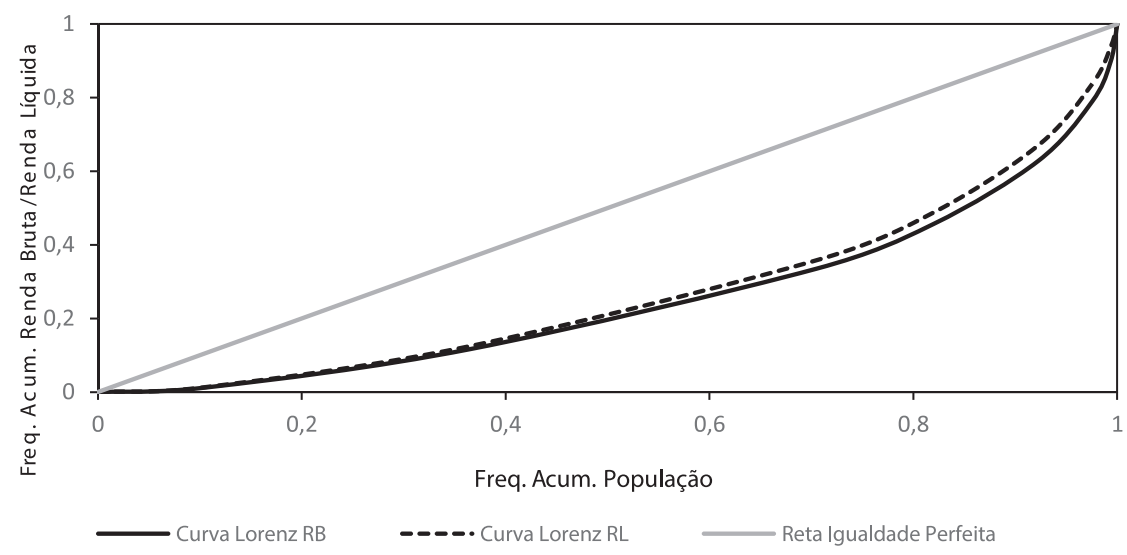

Figura 2 - Curva de Lorenz da Renda Bruta e da Renda Líquida para o ano de 2012 Fonte: PNAD (IBGE) e DW IRPF (RFB) / Elaboração Própria.

Para 2012, tem-se $G_{X}=0,491$ e $G_{X-T}=0,458$.

A partir das Equações (2) e (3) obtém-se $\Pi^{R S}=-0,033$ e $\Pi^{M T}=1,065$.

Ambos os resultados mostram que o IRPF brasileiro é um imposto progressivo também sob a ótica redistributiva. $\mathrm{O}$ índice de Pfähler segue o mesmo enfoque dado ao índice de Suits, sendo calculado como o dobro da área entre a curva de concentração relativa para a renda líquida e a reta da tributação proporcional. Desse modo, $\Pi^{P A}=-0,055$, mostrando também a progressividade sob a perspectiva da curva de concentração relativa. A Tabela 5 mostra o cálculo dos índices de efeito redistributivo para os anos de 2006 a 2012. 
Tabela 5 - Índices de Reynolds-Smolensky, Musgrave-Thin e Pfähler para 2006 a 2012

\begin{tabular}{lllllcll}
\hline & $g(\%)$ & $G_{X}$ & $G_{X-T}$ & $\Pi^{R S}$ & $\Pi^{R S} / G_{X}(\%)$ & $\Pi^{M T}$ & $\Pi^{P A}$ \\
\hline $\mathbf{2 0 0 6}$ & 5,35 & 0,534 & 0,509 & $-0,025$ & 4,68 & 1,054 & $-0,044$ \\
$\mathbf{2 0 0 7}$ & 5,89 & 0,521 & 0,493 & $-0,028$ & 5,37 & 1,059 & $-0,049$ \\
$\mathbf{2 0 0 8}$ & 6,05 & 0,518 & 0,488 & $-0,030$ & 5,79 & 1,061 & $-0,051$ \\
$\mathbf{2 0 0 9}$ & 5,70 & 0,510 & 0,482 & $-0,028$ & 5,49 & 1,058 & $-0,049$ \\
$\mathbf{2 0 1 0}$ & 6,43 & 0,513 & 0,481 & $-0,032$ & 6,24 & 1,066 & $-0,055$ \\
$\mathbf{2 0 1 1}$ & 6,62 & 0,494 & 0,460 & $-0,034$ & 6,88 & 1,068 & $-0,058$ \\
$\mathbf{2 0 1 2}$ & 6,37 & 0,491 & 0,458 & $-0,033$ & 6,72 & 1,065 & $-0,055$ \\
\hline
\end{tabular}

Legenda: g $(\%)=$ participação percentual da arrecadação do IRPF em relação à renda bruta total; $G_{X}=$ Índice de Gini da renda bruta; $G_{X-T}=$ Índice de Gini da renda líquida (renda bruta menos IRPF); $\Pi^{R S}=$ Índice de Reynolds-Smolensky $\left(G_{X-T}-G_{X}\right) ; \Pi^{R S} / G_{X}(\%)=$ Modificação percentual do índice de Gini da renda bruta após incidência do IRPF; $\Pi^{M T}=$ Índice de Musgrave-Thin; e $\Pi^{P A}=$ Índice de Pfähler.

Fonte: Elaboração Própria.

O que se observa na Tabela 5 é a correlação entre a representatividade percentual do IRPF em relação à renda bruta, evidenciada pela alíquota média total $g$ e a capacidade redistributiva do imposto. $\mathrm{O}$ ano de 2011 foi o ano em que todos os indicadores de progressividade foram os maiores, correspondendo, portanto, ao maior valor de alíquota média total. O ano de 2006 registrou os menores valores de todos os índices. O que se percebe é uma elevação tênue da capacidade redistributiva do IRPF que, em 2012, reduziu o índice de Gini da renda bruta em 6,72\% e para o período de 2006 a 2012 houve um incremento de 2,04\% na redução do referido índice. Desse modo, quanto maior for a representatividade arrecadatória do IRPF, maior será seu potencial distributivo conforme já demonstrado nas Equações (4) e (5), a despeito do extremo desvio da proporcionalidade do tributo como demonstram os valores obtidos para os índices de Kakwani e Suits. 
5.4. Decomposição da progressividade para o IRPF Trabalho: efeito base e efeito alíquota

O imposto de renda da pessoa física incidente sobre os rendimentos do trabalho possui uma estrutura complexa derivada das tradições histórico-culturais de cada país. Entender as diferentes contribuições de cada parcela (deduções, créditos, isenções, entre outros) da estrutura do imposto para sua progressividade geral é uma tarefa importante para o formulador de política tributária, porque ele saberá antever as consequências de suas propostas e quais grupos de cidadãos serão favorecidos por elas. Em geral, há três tipos de parcelas que determinam a progressividade do imposto de renda da pessoa física: as deduções a partir da renda bruta; a estrutura de alíquotas aplicada à renda tributável; e as deduções aplicáveis ao próprio imposto devido. A maior ou menor progressividade do tributo pode advir de qualquer uma das parcelas citadas, variando conforme a legislação aplicável a cada jurisdição. Dessa forma, a maioria dos estudos adota a decomposição do índice de Kakwani proposta por Pfähler (1990), dentre outras possíveis, justamente porque ela segue a lógica da apuração do imposto de renda da pessoa física.

Seja então a seguinte estrutura de apuração do IRPF trabalho, com os termos em inglês, entre parênteses, seguindo a nomenclatura dos estudos de progressividade das deduções do IRPF no âmbito dos países da OCDE:

i) Imposto Apurado $=I A$; ii) Imposto Devido Final $=I D$; iii $r()=$. estrutura de alíquotas aplicável ao rendimento tributável líquido $(R T L)$; iv) $R T B=$ rendimento tributável bruto (antes das deduções); v) $E=$ isenções (exemptions); vi) $A=$ deduções de valor fixo da RTB (allowances); vii) $D(\mathrm{RTB})$ = deduções da $R T B$ que são funções da renda do declarante (deductions); viii) $\mathrm{C}=$ deduções do imposto apurado ou créditos ao contribuinte (taxcredits).

Assim, a renda tributável líquida pode ser escrita como:

$$
R T L=R T B-E-A-D(R T B)
$$

O imposto apurado será:

$$
I A=r(R T B-E-A-D(R T B))
$$


E o imposto devido final será:

$$
I D=r(R T B-E-A-D(R T B))-C
$$

No caso do Brasil, as deduções do imposto apurado possuem baixíssima representatividade econômica, de forma que far-se-á a decomposição a partir da Equação (9), considerando-se que o imposto apurado será o imposto devido, visto que $C=0$ na Equação (10).

A progressividade do imposto apurado resulta, de um lado, do efeito da estrutura de alíquotas aplicável à renda tributável líquida (efeito alíquota ou progressividade direta) e de outro das deduções legalmente permitidas à renda tributável bruta (efeito base ou progressividade indireta). Assim:

$$
\Pi_{I A}^{K}=C_{I A}-G_{R T B}=\left(C_{I A}-C_{R T L}\right)+\left(C_{R T L}-G_{R T B}\right)
$$

O primeiro termo da Equação (11) mede a progressividade advinda da aplicação da estrutura das alíquotas à renda tributável líquida. Desse modo é a medida do efeito alíquota, e corresponde à diferença entre o coeficiente de concentração do imposto apurado e da renda tributável líquida. Logo:

$$
\Pi_{R}^{K}=C_{I A}-C_{R T L}
$$

O segundo termo da Equação (11) mede a progressividade oriunda da estrutura de deduções aplicáveis à renda tributável bruta, sendo, portanto, a medida do efeito base calculada como a diferença entre o coeficiente de concentração da renda tributável líquida e o índice de Gini da renda tributável bruta. Utilizando-se a Equação (7) e alguns resultados auxiliares pode-se mostrar que:

$$
\begin{gathered}
C_{R T L}-G_{R T B}=\frac{1}{1-e-a-d}\left[e\left(G_{R T B}-C_{E}\right)+a\left(G_{R T B}-C_{A}\right)+d\left(G_{R T B}-C_{D}\right)\right]= \\
\frac{e}{1-e-a-d} \Pi_{E}^{K}+\frac{a}{1-e-a-d} \Pi_{A}^{K}+\frac{d}{1-e-a-d} \Pi_{D}^{K}
\end{gathered}
$$


Onde: $\underline{e}$ é a alíquota média das isenções e $\Pi_{E}^{K}$ mede a desproporcionalidade das isenções; $\underline{a}$ é a alíquota média das deduções fixas e $\Pi_{A}^{K}$ mede a desproporcionalidade dessas deduções; $\underline{d}$ é a alíquota média das deduções dependentes da renda do declarante e $\Pi_{D}^{K}$ mede a desproporcionalidade dessas deduções. O raciocínio é o mesmo para o índice de Kakwani, sendo que valores positivos representarão progressividade das deduções e corresponderão a um benefício maior aos contribuintes de renda mais baixa.

A aplicação das Equações (11), (12) e (13) à estrutura do IRPF brasileiro é imediata. Desse modo, utilizando-se a Equação (11) serão calculados os efeitos alíquota e base para o IRPF brasileiro. Além disso, utilizando-se a Equação (13) calculam-se as contribuições de cada dedução para o efeito base total.

As deduções por dependentes e com gastos em educação aproximam-se mais das deduções de valor fixo (allowances), sendo as demais deduções relacionadas à renda do declarante. Entretanto, isso é irrelevante para a aplicação da Equação (13). Para fins de facilidade na apresentação dos resultados, as deduções foram agrupadas da seguinte forma: DS = Desconto Simplificado; $\mathrm{CPO}=$ Contribuição Previdenciária Oficial; DM = Despesas Médicas; DI = Despesas com Dependentes e Instrução; e $\mathrm{O}$ (Outras) = Despesas de Contribuição para a Previdência Privada, Livro-Caixa e Pensão Alimentícia.

Cabem aqui duas ressalvas metodológicas. Para esse cálculo foram utilizadas somente as informações constantes das declarações de IRPF e, portanto, a renda tributável bruta não é a da PNAD. Dessa forma, os valores dos índices de Kakwani para o IRPF trabalho não coincidirão com os mostrados na Tabela 3. Além disso, para a construção da Tabela 3 foi adicionado o $13^{\circ}$ salário ao IRPF Trabalho, o que não ocorre aqui. De qualquer forma, os resultados obtidos continuam relevantes para o entendimento de como se comportam o efeito alíquota e o efeito base no IRPF brasileiro. Outra questão metodológica é que o valor informado das deduções não sofre nenhuma crítica pelo programa e foi alvo de depuração. 
As Tabelas 6 e 7 mostram os dados utilizados para os cálculos da progressividade direta e indireta do IRPF trabalho para o ano de 2012.

Tabela 6 - Quantidade de Declarações, RTB, RTL e ID para o ano de 2012

Valores em $R \$$ milhões

\begin{tabular}{ccrrr}
\hline Faixa de Rend. Anual & $\begin{array}{c}\text { Quant. } \\
\text { Declarações }\end{array}$ & \multicolumn{1}{c}{ RTB } & \multicolumn{1}{l}{ RTL } & \multicolumn{1}{c}{ IA = ID } \\
\hline Até $\mathrm{R} \$$ 3.732,00 & 1.304 .948 & 184,75 & 150,25 & 0,00 \\
De 3.732,01a R $\$ 7.464,00$ & 497.333 & $3.147,41$ & $2.595,36$ & 0,04 \\
De 7.464,01 a 14.928,00 & 1.034 .305 & $10.119,61$ & $8.402,82$ & 0,26 \\
De 14.928,01 a 22.392,00 & 2.163 .528 & $37.343,19$ & $30.812,08$ & 1,08 \\
De 22.392,01 a 37.320,00 & 7.718 .283 & $194.757,64$ & $149.515,54$ & 829,92 \\
De 37.320,01 a 74.640,00 & 7.166 .909 & $301.317,62$ & $220.316,60$ & $10.018,56$ \\
De 74.640,01 a 149.280,00 & 3.456 .902 & $260.846,68$ & $199.151,47$ & $26.797,69$ \\
Acima de 149.280,00 & 2.275 .345 & $382.749,84$ & $314.925,64$ & $68.643,81$ \\
\hline TOTAL & 25.617 .553 & $1.190 .466,73$ & $925.869,76$ & $106.291,36$ \\
\hline
\end{tabular}

Legenda: RTB = Renda Tributável Bruta; RTL = Renda Tributável Líquida (igual a RTB menos as deduções legais do IRPF); IA = Imposto Apurado e ID = Imposto Devido. No caso brasileiro, IA = ID. Fonte: DW IRPF (RFB) / Elaboração Própria.

Tabela 7 - Valores das deduções do RTB para o ano de 2012

Valores em $R \$$ milhões

\begin{tabular}{crrrrr}
\hline Faixa de Rend. Anual & DS & CPO & DM & DI & Outras \\
\hline Até $\mathrm{R} \$$ 3.732,00 & 16,66 & 14,08 & 0,37 & 3,12 & 0,26 \\
De 3.732,01a R $\$ 7.464,00$ & 415,53 & 93,57 & 20,27 & 18,71 & 3,96 \\
De 7.464,01 a 14.928,00 & $1.266,35$ & 214,49 & 93,06 & 120,34 & 22,54 \\
De 14.928,01 a 22.392,00 & $5.069,12$ & 471,10 & 210,02 & 730,48 & 50,39 \\
De 22.392,01 a 37.320,00 & $27.078,62$ & $3.147,38$ & $3.546,08$ & $10.330,27$ & $1.139,75$ \\
De 37.320,01 a 74.640,00 & $31.381,75$ & $12.805,42$ & $11.726,59$ & $20.765,06$ & $4.322,20$ \\
De 74.640,01 a 149.280,00 & $20.321,46$ & $9.726,65$ & $12.314,54$ & $12.176,63$ & $7.155,93$ \\
Acima de 149.280,00 & $7.509,70$ & $15.656,96$ & $15.258,91$ & $7.740,75$ & $21.657,87$ \\
\hline TOTAL & $93.059,20$ & $42.129,65$ & $43.169,84$ & $51.885,37$ & $34.352,91$ \\
\hline
\end{tabular}

Legenda: $\mathrm{DS}=$ Desconto Simplificado; $\mathrm{CPO}=$ Contribuição Previdenciária Oficial; DM = Despesas Médicas; DI = Despesas com Dependentes e Instrução; e O (Outras) = Despesas de Contribuição para a Previdência Privada, Livro-Caixa e Pensão Alimentícia.

Fonte: $D W$ IRPF (RFB) / Elaboração Própria. 
Tem-se, para 2012: $C_{I A}=C_{I D}=0,7850 ; C_{R T L}=0,4397 ; G_{R T B}=$ 0,4309

Logo, da equação (12) o efeito alíquota será: $\Pi_{R}^{K}=0,3453$

E o efeito base será: $\Pi_{B}^{K}=0,0088$ e a progressividade total será: $\Pi_{I D}^{K}$ $=0,3541$

Esses índices permitem concluir que as deduções são proporcionais, isto é, praticamente não alteram a distribuição da renda tributável líquida em relação à renda tributável bruta e que, basicamente, toda a progressividade do imposto advém da estrutura das alíquotas. A Tabela 8 mostra a evolução desses índices.

A observação da tabela mostra uma grande estabilidade do IRPF em termos de efeito base e efeito alíquota. No caso brasileiro, a progressividade decorre totalmente da estrutura de alíquotas, sendo que, no período de 2006 a 2008, o efeito base foi levemente regressivo, passando a levemente progressivo, mas com magnitudes bastante próximas a zero.

Tabela 8 - Efeito base e Efeito alíquota para o período de 2006 a 2012

\begin{tabular}{lllllll}
\hline & $C_{I D}$ & $C_{R T L}$ & $G_{R T B}$ & $\Pi_{I D}^{K}$ & $\Pi_{R}^{K}$ & $\Pi_{B}^{K}$ \\
\hline 2006 & 0,8418 & 0,4831 & 0,4855 & 0,3563 & 0,3587 & $-0,0024$ \\
2007 & 0,8486 & 0,5046 & 0,5095 & 0,3391 & 0,3440 & $-0,0049$ \\
2008 & 0,8266 & 0,4825 & 0,4832 & 0,3434 & 0,3441 & $-0,0007$ \\
2009 & 0,8257 & 0,4627 & 0,4603 & 0,3654 & 0,3630 & 0,0024 \\
2010 & 0,8045 & 0,4515 & 0,4463 & 0,3582 & 0,3529 & 0,0053 \\
2011 & 0,7927 & 0,4475 & 0,4397 & 0,3530 & 0,3452 & 0,0078 \\
2012 & 0,7850 & 0,4397 & 0,4309 & 0,3541 & 0,3453 & 0,0088 \\
\hline
\end{tabular}

Legenda: $C_{I D}=$ Coeficiente de Concentração do imposto devido; $C_{R T L}=$ Coeficiente de Concentração da renda tributável líquida; $G_{R T B}=$ Índice de Gini da Renda tributável bruta; $\Pi_{I D}^{K}=$ índice de Kakwani do imposto devido; $\Pi_{R}^{K}=$ Índice de Kakwani da estrutura de alíquotas (efeito alíquota); $\Pi_{B}^{K}=$ Índice de Kakwani da estrutura de deduções (efeito base).

Fonte: Elaboração Própria. 
Resta agora aplicar a Equação (13) e desmembrar o efeito base para verificar a progressividade das deduções. A Tabela 9 mostra os resultados.

Tabela 9 - Contribuição de cada dedução para o efeito base total de 2006 a 2012

\begin{tabular}{lllllll}
\hline & $\Pi_{B}^{K}$ & $\Pi_{D S}^{K}$ & $\Pi_{C P O}^{K}$ & $\Pi_{D M}^{K}$ & $\Pi_{D I}^{K}$ & $\Pi_{O}^{K}$ \\
\hline 2006 & $-0,0024$ & 0,0342 & $-0,0075$ & $-0,0124$ & $-0,0036$ & $-0,0131$ \\
2007 & $-0,0005$ & 0,0310 & $-0,0070$ & $-0,0125$ & $-0,0033$ & $-0,0130$ \\
2008 & $-0,0007$ & 0,0246 & $-0,0046$ & $-0,0093$ & 0,0013 & $-0,0130$ \\
2009 & 0,0024 & 0,0245 & $-0,0045$ & $-0,0076$ & 0,0028 & $-0,0127$ \\
2010 & 0,0053 & 0,0255 & $-0,0045$ & $-0,0073$ & 0,0041 & $-0,0125$ \\
2011 & 0,0078 & 0,0247 & $-0,0046$ & $-0,0065$ & 0,0059 & $-0,0118$ \\
2012 & 0,0088 & 0,0259 & $-0,0051$ & $-0,0061$ & 0,0055 & $-0,0115$ \\
\hline
\end{tabular}

Legenda: $\Pi_{B}^{K}=$ Índice de Kakwani da estrutura de deduções (efeito base); $\Pi_{D S}^{K}=$ Índice de Kakwani referente ao desconto simplificado; $\Pi_{C P O}^{K}=$ Índice de Kakwani referente à Contribuição Previdenciária Oficial; $\Pi_{D M}^{K}=$ Índice de Kakwani referente às despesas médicas; $\Pi_{D I}^{K}=$ Índice de Kakwani referente às despesas com dependentes e instrução e $\Pi_{O}^{K}=$ Índice de Kakwani referente às Outras Despesas, quais sejam: Despesas de Contribuição para a Previdência Privada, Livro-Caixa e Pensão Alimentícia.

Fonte: Elaboração Própria.

A Tabela 9 mostra também a estabilidade da participação de cada dedução na progressividade indireta do IRPF. A dedução mais progressiva é o desconto simplificado e as mais regressivas são as outras deduções que representam a soma da contribuição previdenciária privada, livrocaixa e pensão alimentícia. As demais deduções são praticamente proporcionais, sendo que, a partir de 2007, as despesas com dependentes e instrução que eram levemente regressivas passaram a ser levemente progressivas.

As demais deduções são praticamente proporcionais. Com esses resultados se obtém uma visão mais clara da estrutura do IRPF brasileiro, quantificando-se a progressividade de cada componente da base, da própria base e da estrutura de alíquotas. No caso específico do Brasil, a estrutura de alíquotas é responsável por toda a progressividade do imposto. 


\subsection{Comparações internacionais}

Como foi visto na seção 4.2, a grande vantagem dos índices de progressividade global é encapsular em um único número índice a distribuição de renda e dos impostos e permitir a comparação entre os diversos países. Este trabalho adota premissas teóricas e metodológicas similares aos estudos internacionais escolhidos, mas torna-se importante ressaltar que não um padrão que assegure uma comparabilidade absoluta entre os índices calculados.

Os índices de progressividade mais utilizados em comparações internacionais são o de Kakwani e Reynolds-Smolensky, havendo somente o trabalho de Mathews (2014), utilizando o índice de Suits. Para o IRPF na América Latina foram encontrados os estudos de Jorratt (2010) para o Chile e Roca (2010) para o Uruguai. Em geral, os trabalhos procuram avaliar a progressividade de todo o sistema tributário ao invés de um único tributo.

No âmbito da OCDE há vários estudos abordando o IRPF e apresentando sua decomposição na forma mostrada na seção 6.4, sendo que as comparações, nesse caso, devem ser feitas com a devida cautela, dada a especificidade da legislação de cada país e os objetivos que se deseja atender com o respectivo alívio fiscal. Há também estudos empíricos para alguns outros países que serão incorporados às comparações feitas. A Tabela 10, a seguir, mostra os resultados obtidos por Verbist (2013), relativos ao ano de 2008, para 15 países da OCDE e mais os resultados para o Brasil obtidos anteriormente. ${ }^{5}$

\footnotetext{
${ }^{5}$ Os trabalhos internacionais utilizam, em geral, 10 faixas. Os trabalhos da OCDE calculam os índices a partir dos microdados sem reportar explicitamente a quantidade de faixas. Infelizmente não há um padrão mínimo para que haja comparabilidade segura, o que pode criar algum viés nos dados aqui estimados. Por essa razão, esta comparação deve ser vista com a devida reserva. Agradecemos a um parecerista anônimo por chamar a atenção para este fato.
} 
Tabela 10 - Índices de progressividade do IRPF para países da OCDE e Brasil 2008

\begin{tabular}{lcccccc}
\hline & $g(\%)$ & $G_{X}$ & $G_{X-T}$ & $\left|\Pi^{R S}\right|$ & $\Pi^{R S} / G_{X}(\%)$ & $\Pi_{I R P F}^{K}$ \\
\hline Alemanha & 30,19 & 0,3321 & 0,2671 & 0,0650 & 19,6 & 0,1727 \\
Áustria & 27,87 & 0,3100 & 0,2497 & 0,0602 & 19,4 & 0,1634 \\
Bélgica & 29,47 & 0,3150 & 0,2322 & 0,0828 & 26,3 & 0,2082 \\
Dinamarca & 34,64 & 0,2781 & 0,2377 & 0,0405 & 14,5 & 0,0816 \\
Espanha & 15,07 & 0,3263 & 0,2919 & 0,0344 & 10,5 & 0,2025 \\
Finlândia & 27,74 & 0,3034 & 0,2543 & 0,0491 & 16,2 & 0,1328 \\
França & 20,18 & 0,3075 & 0,2731 & 0,0344 & 11,2 & 0,1450 \\
Grécia & 19,01 & 0,3618 & 0,3278 & 0,0340 & 9,4 & 0,1901 \\
Holanda & 30,81 & 0,3128 & 0,2651 & 0,0476 & 15,2 & 0,1142 \\
Irlanda & 17,19 & 0,3328 & 0,2680 & 0,0648 & 19,5 & 0,3205 \\
Itália & 25,52 & 0,3527 & 0,3071 & 0,0457 & 12,9 & 0,1388 \\
Luxemburgo & 21,25 & 0,2942 & 0,2480 & 0,0463 & 15,7 & 0,1797 \\
Portugal & 18,36 & 0,3954 & 0,3494 & 0,0459 & 11,6 & 0,2122 \\
Reino Unido & 23,78 & 0,3638 & 0,3109 & 0,0529 & 14,5 & 0,1780 \\
Suécia & 28,98 & 0,2698 & 0,2330 & 0,0368 & 13,7 & 0,0976 \\
\hline Brasil & $\mathbf{6 , 0 5}$ & $\mathbf{0 , 5 1 8}$ & $\mathbf{0 , 4 8 8}$ & $\mathbf{0 , 0 3 0}$ & $\mathbf{5 , 8}$ & $\mathbf{0 , 4 5 8}$ \\
\hline
\end{tabular}

Legenda: $\mathrm{g}(\%)=$ participação percentual da arrecadação do IRPF em relação à renda bruta total; $G_{X}=$ Índice de Gini da renda bruta; $G_{X-T}=$ Índice de Gini da renda líquida (renda bruta menos IRPF); $\left|\Pi^{R S}\right|=$ =Módulo Índice de Reynolds-Smolensky; $\Pi^{R S} / G_{X}(\%)=$ Modificação percentual do índice de Gini da renda bruta após incidência do IRPF; $\mathrm{e} \Pi_{I R P F}^{K}=$ Índice de Kakwani do IRPF.

Fonte: Verbist (2013) / Elaboração Própria.

Os dados apresentados na Tabela 10 permitem concluir que os países da OCDE não precisam de tanto foco na renda mais alta, visto que sua distribuição de renda bruta (antes do imposto) é bem melhor que a do Brasil. O maior índice de Kakwani para os países selecionados é o da Irlanda, sendo o nosso índice 43\% maior. Quanto ao potencial redistributivo do IRPF, a primeira coluna já é um bom indício que o índice de Reynolds -Smolensky do Brasil seria o menor, apesar de não se estar tão distante do índice apresentado pela Grécia, provavelmente porque a distribuição da renda bruta não é das melhores e a desproporcionalidade do imposto também não é alta. Portanto, o potencial redistributivo do IRPF brasileiro fica claramente limitado por sua representatividade arrecadatória, apesar da acentuada desproporcionalidade do tributo. 
Alguns resultados obtidos por Verbist (2013) sobre a composição do efeito base e efeito alíquota merecem ser citados. Em todos os países da Tabela 10 a estrutura de alíquotas contribui positivamente para a progressividade do IRPF, mas não parece haver relação entre a progressividade, o número de faixas e a alíquota marginal mais elevada. Em 10 dos 15 países, a estrutura de alíquotas é a parcela que mais contribui para a progressividade total do IRPF, sendo que na Irlanda, em Portugal e no Reino Unido a maior contribuição da progressividade advém do efeito base. Na Áustria e na Bélgica há um claro equilíbrio na contribuição do efeito base e do efeito alíquota para a progressividade do IRPF. Interessante registrar que para o Brasil a progressividade é originada integralmente da estrutura de alíquotas do imposto, o que foge à regra dos países da OCDE. De qualquer forma, esse é um quesito de difícil julgamento dadas as idiossincrasias de cada legislação.

A Tabela 11, a seguir, mostra alguns resultados para países selecionados segundo os trabalhos de Nyamongo e Schoeman (2007); Hyun e Lim (2005); Jorratt (2010); Roca (2010) e Mathews (2014). O exame da tabela mostra o quão difícil seria tirar conclusões olhando-se para apenas um índice de progressividade. A tabela mostra países com renda próxima ao Brasil, exceto Coreia do Sul e Estados Unidos. O que se verifica para os países em desenvolvimento é um índice de Gini da renda bruta elevado, o que, em tese, obrigaria os países a se valer da desproporcionalidade na incidência do IRPF.

Tabela 11- Índices de progressividade do IRPF para países selecionados

\begin{tabular}{ccccccc}
\hline & $G_{X}$ & $G_{X-T}$ & $\Pi^{R S}$ & $\Pi^{M T}$ & $\Pi^{K}$ & $\Pi^{S}$ \\
\hline África do Sul (2000) & 0,626 & 0,578 & $-0,048$ & 1,083 & 0,145 & --- \\
África do Sul (2004) & 0,592 & 0,575 & $-0,017$ & 1,030 & 0,132 & $\cdots$ \\
\hline Brasil (2006) & 0,518 & 0,488 & $-0,030$ & 1,054 & 0,458 & 0,788 \\
\hline Chile (2003) & 0,5791 & 0,5584 & $-0,021$ & 1,049 & 0,389 & --- \\
Coréia do Sul (2000) & 0,4007 & 0,3789 & $-0,022$ & 1,036 & 0,426 & --- \\
Estados Unidos (2006) & --- & --- & $-0,036$ & 1,068 & 0,364 & 0,454 \\
Estados Unidos (2010) & --- & --- & $-0,034$ & 1,060 & 0,412 & 0,512 \\
Paquistão (2005) & --- & --- & $-0,011$ & --- & 0,564 & $\cdots$ \\
Uruguai (2008) & 0,4995 & 0,4874 & $-0,012$ & 1,024 & 0,364 & --- \\
\hline
\end{tabular}

Legenda: $G_{X}=$ Índice de Gini da renda bruta; $G_{X-T}=$ Índice de Gini da renda líquida (renda bruta menos IRPF); $\Pi^{R S}=$ Índice de Reynolds-Smolensky; $\Pi^{M T}$ = Índice de Musgrave-Thin; $\Pi^{K}=$ Índice de Kakwani e $\Pi^{S}=$ Índice de Suits.

Fonte: Nyamongo e Schoeman (2007); Hyun e Lim (2005); Jorratt (2010); Roca (2010) e Mathews (2014)/ Elaboração Própria. 
Esse, entretanto, não parece ser o caso da África do Sul como sugerem os índices de Kakwani apresentados. Por isso, o poder redistributivo é baixo para 2004, ainda que, segundo Nyamongo e Schoeman (2007), o IRPF represente em torno de $30 \%$ da arrecadação total dos impostos. Já o Paquistão apresenta um índice de Kakwani superior ao do Brasil, mas padece de uma capacidade redistributiva baixa, provavelmente devido à pouca representatividade arrecadatória do imposto. Uruguai e Chile parecem sofrer do mesmo problema brasileiro, apesar dos índices de Kakwani mais baixos, o que poderia sugerir a possibilidade de um maior avanço do tributo sobre as rendas mais altas nesses países. Estados Unidos e Coreia do Sul possuem índices de Kakwani elevados frente aos países da OCDE mostrados na Tabela 11, mas a Coreia redistribui menos que os Estados Unidos, provavelmente devido à representatividade da receita do IRPF. Fica evidente a maior dificuldade dos países com renda média mais baixa em explorar o potencial redistributivo de seu IRPF, na medida em que a receita tributária oriunda do tributo não tem a mesma representatividade que nos países de renda alta. Isto posto, uma questão que permanece em aberto, mas a qual tem sido alvo de debate recente conforme Silveira et al. (2013) e Higgins e Pereira (2014), é como aumentar a progressividade da tributação direta, visto a limitação do IRPF no que tange à renda média do país. Um caminho natural seria utilizar de maneira mais efetiva os impostos sobre a propriedade, tais como o Imposto sobre a Propriedade Predial e Territorial Urbana (IPTU), o Imposto sobre Transmissão Causa Mortis e Doação de Quaisquer Bens e Direitos (ITCMD), o Imposto sobre a Propriedade de Veículos Automotores (IPVA), o Imposto sobre a Propriedade Territorial Rural (ITR) e o próprio IRPF, considerandose a possibilidade da tributação de lucros e dividendos, por exemplo. Neste trabalho apenas contextualizamos esse tema sem a pretensão de apresentar uma resposta, ainda que geral, à questão posta ao debate acadêmico.

\section{Conclusão}

O imposto de renda da pessoa física no Brasil é bastante progressivo quando se utiliza um índice conhecido de progressividade local. Em termos de alíquotas efetivas, a alíquota efetiva (média) total foi 9,2\% em 2012, bastante próxima da alíquota marginal mínima de 7,5\% para os rendimentos do trabalho e bem distante da alíquota mínima de 15\% 
para os rendimentos do capital. Isso mostra que a grande maioria da população não paga imposto ou paga a alíquotas efetivas bem inferiores às previstas na legislação, evidenciando a aplicação efetiva do princípio da capacidade de pagamento previsto na Constituição Federal de 1988.

Em termos de medidas de progressividade global, quando são utilizados índices de desvio da proporcionalidade (Kakwani e Suits) para efetuar essa avaliação, a conclusão é a mesma. O único país que apresentou um índice de Kakwani maior que o nosso foi o Paquistão. Já para uma amostra de 15 países da OCDE, o índice de Kakwani do Brasil foi 43\% maior que o da Irlanda, país com o maior índice da amostra. Portanto, isso mostra que o nosso imposto concentra seus esforços arrecadatórios nas faixas superiores de renda. A curva de concentração dos impostos, apresentada na Figura 2, ganha impulso após o último decil da população. As pessoas com faixa de renda acima de 20 salários mínimos mensais, aproximadamente 738.000 contribuintes respondem por $68,3 \%$ do imposto de renda total, $64,7 \%$ do IRPF trabalho e $89,9 \%$ do IRPF capital para o ano de 2012, o que é bastante emblemático e ratifica os achados de Rossi (1983) e Soares et al. (2010).

No que concerne às medidas de progressividade calcadas no efeito redistributivo do tributo, o país apresentou um índice de ReynoldsSmolensky negativo $(-0,033)$ para 2012 , evidenciando também sua progressividade. Isso mostra que há uma redução de $6,7 \%$ no índice de Gini após a incidência do imposto. No entanto, nessa perspectiva o índice brasileiro fica abaixo dos países com renda mais elevada como os países da OCDE. Da amostra de quinze países da citada organização, a Grécia conseguiu reduzir o índice de Gini após a incidência do IRPF em $9,4 \%$ e a Espanha em 10,5\% em 2008, ao passo que nossa redução foi de apenas $5,8 \%$ para o mesmo ano. Em relação a países com renda próxima a nossa, como Chile, Uruguai, África do Sul e Paquistão, o Brasil apresentou índices redistributivos superiores. Isso mostra as dificuldades dos países de renda média, entre eles o Brasil, em fazer uso da tributação direta. Nesses casos, os índices redistributivos são mais baixos devido à baixa representatividade da arrecadação do imposto frente à renda bruta total do país.

Por fim, um outro resultado importante obtido graças à utilização dos dados tributários foi a decomposição da estrutura de apuração do imposto apurado para os rendimentos do trabalho. Nesse caso, a progressividade do tributo brasileiro advém integralmente da estrutura de 
alíquotas, sendo que a estrutura das deduções do rendimento bruto é proporcional, e, portanto, neutra em termos de progressividade. A dedução mais progressiva foi o desconto simplificado e o conjunto de deduções mais regressivo foi representado pelas despesas de Contribuição para a Previdência Privada, Livro-Caixa e Pensão Alimentícia. Essa é uma característica do tributo brasileiro que não é compartilhada pela maioria dos países da OCDE, embora a estrutura de alíquotas também contribua para a progressividade em boa parte da amostra analisada nesse estudo.

Algumas questões pertinentes emergem dos achados expostos anteriormente e trazem insumo para pesquisas futuras: Há de fato uma correlação entre nível de renda per capita e a variável $g$ (razão entre a arrecadação do imposto de renda e a renda bruta total)? Qual é o determinante dessa correlação? E o nível de desigualdade afeta tal correlação? Tais perguntas abrem novas perspectivas de investigação. ${ }^{6}$

Assim, este artigo contribui para a literatura nacional sobre incidência tributária e apresenta achados que darão subsídio tanto a novas pesquisas, quanto aos que desejam se valer do IRPF como instrumento de política tributária. A utilização de dados tributários torna nossa contribuição relevante à discussão do tema, dada a fragilidade de alguns aspectos das pesquisas censitárias, como os rendimentos ligados à remuneração do capital.

Dessa forma, o IRPF brasileiro demonstra ser um tributo capaz de trazer recursos para o Estado a partir dos contribuintes de renda mais elevada, contribuindo, de forma modesta, para equalizar a distribuição de renda da população. Ainda que a finalidade precípua da tributação não seja melhorar a distribuição de renda, o IRPF cumpre honrosamente o papel de tentar contrabalançar o perfil regressivo da tributação indireta no país.

6 Agradecemos a um parecerista anônimo por nos chamar atenção a esses importantes desdobramentos de nosso trabalho. 


\section{Referências}

AZEVEDO, M. C. M. D. Os Impactos das Transferências de Rendas Líquidas às Famílias sobre as desigualdades. 2003. 147p. Tese (Doutorado em Economia) - Departamento de Economia, Universidade de Brasília, Brasília, 2003.

BARROS, R. et al. Determinantes da Queda na Desigualdade de Renda no Brasil. Rio de Janeiro: IPEA, 2010. (Texto para discussão n. 1460).

GOÑI, E.; López, J. H.; Servén, L. Fiscal Redistribution and Income Inequality in Latin America. Policy Research Working Paper 4487. The World Bank, 2008.

HIGGINS, S.; Pereira, C. The effects of Brazil's taxation and social spending on the distribution of household income. Public Finance Review, v. 42 (3): 346-367, 2014.

HYUN, J. K.; Lim, B. The Financial Crisis and Income Distribution in Korea: The Role of Income Tax Policy. The Journal of the Korean Economy, v.6 (1): 51-65, 2005.

IMMERVOLL, H. et al. Simulating Brazil's tax-benefit systemusing BRAHMS, the Brazilian household microsimulation model. Revista de Economia Aplicada, v.10 (2): 203-223, 2006.

JORRAT, M. Equidad Fiscal en Chile: UnAnálisis de laIncidencia Distributiva de losImpuestos y el Gasto Social. In: Equidad Fiscal enBrasil, Chile, Paraguay y Uruguay. Serie de Equidad Fiscal Del BID, 2010. Parte II, p.106-177.

KAKWANI, N. C. Measurement of Tax Progressivity: An International Comparison. The Economic Journal, v.87 (345):71-80, 1977.

KESSELMAN, J.R.; Cheung, R. Tax Incidence, Progressivity and Inequality in Canada. Canadian Tax Journal, v.52 (3):709-789, 2004.

KIM, K.; Lambert, P.J. Redistributive Effect of US Taxes and Public Transfers, 1994-2004, Public Finance Review, v.37, n.1, p.3-26, 2009.

LAMBERT, P. J. The Distribution and Redistribution of Income. $3^{\text {rd }}$. ed. Manchester: Manchester University Press, 2001.

MATHEWS, T. Historical trends in the degree of federal income tax progressivity in the United States. The Social Science Journal, v.51, n.1, p. 90-99, 2014.

MUSGRAVE, A.M.; Musgrave, P.B. Finanças Públicas: Teoria e Prática. São Paulo: Editora Campus, 1980.

MUSGRAVE, R. A.; Thin, T. Income Tax Progression, 1929-48. Journal of Political Economy, v. 56 (6): 498-514, 1948.

NORREGAARD, J. Progressivity of income tax systems. OECD Economic Studies, v. 15, p. 83-110, 1990.

NYAMONGO, M. E.; Schoeman, N. J. Tax Reform and the Progressivity of Personal Income Tax in South Africa. South African Journal of Economics, v.75(3): 478-495, 2007.

PAES, N. E Bugarin, M. Parâmetros tributários da economia brasileira. Estudos Econômicos, v.36(4): 699-720, 2006

PATUROT, D.; Mellbye, K.; Brys, B. Average Personal Income Tax Rate and Tax Wedge Progression in OECD Countries. OECD Taxation Working Papers, n. 15, OECD Publishing, 2013.

PAYERAS, J. A. P. Análise da Progressividade da Carga Tributária sobre a População Brasileira. Pesquisa e Planejamento Econômico, v.40(2):153-186, 2010.

PFÄHLER, W. Relative concentration curve: functional form and measures of non-proportionality. Bulletin of Economic Research, v. 37, p.201-211, 1985.

PFÄHLER, W. Redistributive Effect of Income Taxation: Decomposing Tax Base and Tax Rate Effects. Bulletin of Economic Research, v.42(2): 121-129, 1990.

PIKETTY, T.; Saez, E. How Progressive is the U.S. Federal Tax System? A Historical and International Perspective. Journal of Economic Perspectives, v. 21(1): 3-24, 2007. 
REYNOLDS, M.; Smolensky, E. Public Expenditures, Taxes, and the Distribution of Income: The United States, 1950, 1961, 1970. New York: Academic Press, 1977.

ROCA, J. Equidad Fiscal em Uruguay: Cuánto y cómo modifica el Estado elbienestar de losuruguayos. In: Equidad Fiscal en Brasil, Chile, Paraguay y Uruguay. Serie de Equidad Fiscal Del BID, 2010. Parte IV, p.240-298.

ROCHA, S. O Impacto distributivo do imposto de renda sobre a desigualdade de renda das famílias. Pesquisa e Planejamento Econômico, v.32(1): 73-105, 2002.

RODRIGUES, J. J. Carga Tributária sobre os Salários. Secretaria da Receita Federal, Brasília, 1998 (Texto para Discussão n.1).

ROSSI, J. W. A progressividade do IRPF e o seu efeito redistributivo. Pesquisa e Planejamento Econômico, v.13(3): 905-919, 1983.

SILVEIRA, F. G. Tributação, Previdência e Assistência Sociais: Impactos Distributivos. In: CASTRO, Jorge Abraão de; SANTOS, Cláudio H. M. dos; RIBEIRO, José A. C. (org.). Tributação e Equidade no Brasil: um registro da reflexão do Ipea no biênio 2008-2009. Brasília: IPEA, 2010. cap.2, p. 67-124.

SILVEIRA, F. et al. Fiscal equity: distributional impacts of taxation and social spending in Brazil. IPC-IG Working Papers, n. 115, 2013.

SIQUEIRA, R. B.; Nogueira, J. R.; Souza, E. S. Os impostos sobre consumo no Brasil são regressivos? Economia Aplicada, v.4(4): 705-722, 2000.

SIQUEIRA, R. B.; J. R. Nogueira; Souza, E. S. Alíquotas efetivas e a distribuição da carga tributária indireta sobre as famílias no Brasil. XV Prêmio do Tesouro Nacional, Secretaria do Tesouro Nacional, Ministério da Fazenda, 2010.

SLEMROD, J. Tax Progressivity and Income Inequality. Cambridge: Cambridge University Press, 1996.

SOARES, S.; Silveira, F.; Santos, C.; Vaz, F.; Souza, A. O potencial distributivo do imposto de renda - pessoa física (IRPF). In: Castro, J.; Santos, C.; Ribeiro, J. (org.). Tributação e Equidade no Brasil: um registro da reflexão do Ipea no biênio 2008-2009. Brasília: IPEA, 2010. cap.5, p. 213-256.

STIGLITZ, J. E. Economics of the Public Sector. 3rd. ed. New York: W.W Norton \&Company, 2000.

SUITS, D. B. Measurement of Tax Progressivity. The American Economic Review, v.67(4): 747-752, 1977.

VERBIST, G. Redistributive Effect and Progressivity of Taxes: An International Comparison across the EU using EUROMOD. EUROMOD Working Paper n EM5/04, 2004.

VERBIST, G.; Figari, F. The redistributive effect and progressivity of taxes revisited: An International Comparison across the European Union. AIAS, GINI Discussion Paper 88, 2013. 